\title{
Reallocation and Technology: Evidence from the U.S. Steel Industry*
}

\author{
Allan Collard-Wexler and Jan De Loecker \\ NYU and NBER, and Princeton University, NBER and CEPR
}

First version February 2012, Current version August 28, 2012

\begin{abstract}
This paper studies the role of technology and competition in industry-wide productivity growth. We rely on a unique producer-level dataset covering U.S. steel producers between 1963 and 2002 to measure the impact of a drastic new production technology, the minimill, on aggregate productivity. In addition we trace out its associated impact on productivity and market power through increased competition as measured by the reshuffling of market shares over time and across producers. We provide direct evidence that technological change can itself bring about a process of resource reallocation over a long period of time and lead to substantial productivity growth for the industry as a whole. More specifically, we find that the introduction of a new production technology spurred productivity growth through two channels. First, the entry of minimills lead to a slow but steady drop in the market share of the incumbent technology, the vertically integrated producers. Second, while the new technology started out with a significant productivity premium, by the end of the sample minimills and vertically integrated producers are very similar in terms of efficiency. This catching-up process of the incumbents came about from a large within reallocation of resources among vertically integrated plants.
\end{abstract}

Keywords: Productivity; Technology; Competition.

\footnotetext{
*This project was funded by the Center for Economic Policy Studies (CEPS) at Princeton University and the Center for Global Economy and Business (CGEB) at New York University. We would like to thank Jun Wen for excellent research assistance, and Jonathan Fisher for conversations and help with Census Data. We would like to thank Liran Einav, Kathryn Shaw, Chad Syverson and seminar participants at the NBER, NYU, HEC Montreal, and Stanford University for helpful conversations. This paper uses restricted data that was analyzed at the U.S. Census Bureau Research Data Center in New York City. Any opinions and conclusions expressed herein are those of the authors and do not necessarily represent the views of the U.S. Census Bureau. All results have been reviewed to ensure that no confidential information is disclosed.
} 


\section{Introduction}

A large literature has emphasized the role of the reallocation of resources across producers in aggregate productivity growth. Indeed, industry productivity rises not only because the average plant becomes more productive, but due to shifts in inputs from less to more productive plants.

Although by now there is compelling evidence that the reallocation of resources across producers is important in explaining aggregate outcomes (Foster, Haltiwanger, and Krizan, 2001; Bartelsman, Haltiwanger, and Scarpetta, 2009), it has been very hard to identify the exact mechanisms behind it. In this paper we focus on two distinct potential drivers of reallocation, technology and competition, which we directly observe in our data, and verify to what extent they contributed to productivity growth.

Some prominent studies on the triggers of productivity growth are the work of Schmitz (2005) and Olley and Pakes (1996) who study the role of two such triggers: import competition in the iron ore market, and deregulation in the telecommunications market. As well, the work of Hortaçsu and Syverson (2004), Bloom, Eifert, Mahajan, McKenzie, and Roberts (2011), and Jarmin, Klimek, and Miranda (2009) shows that factors such as vertical integration, management, and large retail chains lead to systematic differences in productivity between plants.

To make progress we focus on one particular industry, the U.S. steel sector, for which we have detailed producer-level production and price data in addition to detailed international trade data. Our setting is in particular well suited to directly measure the separate role of technological change and competition in productivity growth. We identify the impact of technology through the introduction of a new production process for steel products, i.e. the entry of minimills, whereas the change in competition is identified through changes in prices and markups and increased import competition. The fact that we observe plant-level data for a forty year period, 1963-2002, allows us to study the long run implications of both technology and competition.

The U.S. steel industry shed about 75 percent of its workforce between 1962 to 2005, or about 400,000 employees. At the same time, steel shipments in 2005 reached the same level of the early sixties. ${ }^{1}$ Thus output per worker has grown by a factor of five, and total factor productivity (TFP) has increased by 38 percent. Over the last three decades, this makes the steel sector one the fastest growing industries among large manufacturing industries, behind only the computer software and equipment industries. We highlight the special features of the U.S. steel industry in Table 1, where we report the change in output, employment and TFP over the period 1972-2002 for the U.S. steel sector and compare it to the mean and median manufacturing sector's experience. ${ }^{2}$

\footnotetext{
${ }^{1}$ Numbers are based on the NBER manufacturing database.

${ }^{2}$ We only consider large industries with more than 10 billion dollars in sales in 2002 .
} 
Table 1 points out the unique feature of the steel industry: the period of impressive productivity growth, 28 percent compared to the median of 3 percent, occurred while the sector contracted by 35 percent. The starkest difference is the drop in employment of 80 percent compared to a decline of 5 percent for the average sector. ${ }^{3}$

\section{[TABLE 1 ABOUT HERE]}

In addition to identifying the exact mechanisms underlying productivity growth which are of interest to a growing literature on reallocation and productivity dispersion, the size of the U.S. steel sector is still non negligible. Although the steel industry has become much smaller in terms of employment, even today it is one of the largest sectors in U.S. manufacturing: in 2007, steel plants shipped over 100 billion dollars, half of which was value added. Therefore understanding the sources of productivity growth in this industry is of independent interest.

The paper is organized as follows. In the next section, we discuss the rich plant-level data from the Census. In section 3 we present five key facts which help guide the empirical analysis which we take up in section 4 . We collect the main findings and discuss future work in a final section.

\section{Data}

We study the production of steel: plants engaged in the production of either carbon or alloy steels. ${ }^{4}$ In particular we rely on detailed Census micro data to investigate the mechanisms underlying the impressive productivity growth in the U.S. steel sector. Our analysis is based on plant-level production data of U.S. steel producers covering the period 1963 to 2002.

We use data provided by the Center for Economics Studies at the United States Census Bureau. Our primary sources are the Census of Manufacturers (henceforth CMF), the Annual Survey of Manufacturers (henceforth ASM), and the Longitudinal Business Database (henceforth LBD). We select plants engaged in the production of steel, coded in either NAICS (North American Industrial Classification) code 33111, or SIC (Standard Industrial Classification) code $3312 .{ }^{5}$ The CMF is sent to all steel mills every five years, while the ASM is sent to about $50 \%$ of plants in non-Census years. However, all plants with over 250 employees are sampled by the ASM, and as such the ASM encompasses over $90 \%$ of the output of the steel sector.

\footnotetext{
${ }^{3}$ This table masks the distinct periods of demand decline and demand recovery in our sample period by reporting the change in output and employment over the entire sample period. We revisit this in great detail in section 3 .

${ }^{4}$ Throughout our analysis we consider 9 different product segments and we introduce the different products in section 2.2 .

${ }^{5}$ Plants occasionally switch in and out of the steel mill sector. In the data appendix, we discuss how to sort out plants that switch sectors, based on how often these plants are coded as steel mills.
} 
In addition, we collect data on the products produced at each plant using the product trailer to the CMF and the ASM. Likewise we collect the materials consumed by these plants from the material trailer to the CMF.

We rely on our detailed micro data to further break up steel mills into two technologies: Minimills (MM, hereafter) and Vertical Integrated (VI, hereafter) Producers. VI production takes place in two steps. The first stage takes place in a blast furnace, which combines coke, iron ore, and limestone to produce pig iron and slag. The pig iron, along with oxygen and fuel, is then used in a basic oxygen furnace (henceforth BOF) to produce steel. ${ }^{6}$ The steel products produced in either MM or VI plants are shaped into sheets, bars, wire, and tube in a rolling mill. These rolling and shaping mills are frequently collocated with steel mills, but can also be freestanding units. ${ }^{7}$

In contrast, MM's are primarily identified by the use of an electric arc furnace (henceforth EAF) to melt down a combination of scrap steel and direct reduced iron. These mills have a far smaller efficient scale, and thus are on average an order of magnitude smaller than vertically integrated producers. As well, historically EAFs were used to produce lower quality steels, such as those used to make steel bars, while virtually all steel sheet (needing higher quality steel), was produced in BOFs. However, since the mid-1980s, innovation in the EAFs have enabled them to produce certain types of steel sheet products as well. ${ }^{8}$

We classify plants into minimills, vertically integrated plants, and rolling mills using their response to a specific questionnaire on steel mills attached to the 1997, 2002, and 2007 CMF. For prior years, we use the material and products produced by each plant to identify MM and VI plants. ${ }^{9}$ Table 2 shows summary statistics for the sample of MM and VI plants.

[TABLE 2 ABOUT HERE]

\section{Key Facts in the U.S. steel sector 1963-2002}

In this section we briefly go over some key facts of the U.S. steel sector. These facts will be important to keep in mind when we analyze the sources of productivity growth.

\section{Fact 1: Two Distinct Periods of Productivity Growth}

From Table 1 we know that the productivity growth in the U.S. steel sector was one of the fastest in the recent history of U.S. manufacturing. To better understand this period of

\footnotetext{
${ }^{6}$ There are also a few open-hearth furnaces in operation during the sample period. However, as of the late 1960's, open-hearth plants only account for a very small portion of output, and the last open-hearth plant closes in 1991. See Oster (1982) for more on the diffusion of BOF mills.

${ }^{7}$ For references on the differences between minimills and vertically integrated plants and the production process for steel, see Fruehan (1998) p.1-12, Crandall (1981) p.5-15.

${ }^{8} \mathrm{EAF}$ 's have a long history in steel making. However, before the 1960 s they were primarily used to produce specialty steels.

${ }^{9}$ More detail on the classification of plants can be found in the Data Appendix.
} 
impressive productivity growth, we plot total output next to labor and capital use in Figure 1. An important observation is that the period of productivity growth came about while the industry as a whole contracted severely: U.S. steel producers sold about 60 billion dollars in 1960, and reached 100 billion dollars in shipments by the early seventies. A decade later only 40 billion dollars were shipped; or put differently the sector's shipments decreased by more than half. ${ }^{10}$

Total employment on the other hand consistently decreased even during the recovery of output in the late eighties and throughout the nineties. Indeed, the employment panel of Figure 1 shows that total employment fell from 500,000 to 100,000 employees. This is one of the sharpest drops in employment experienced of any sector of the U.S. economy. By the year 2000, the steel industry employs a fifth as much as in 1960, while production of steel changed from 130 million tons in 1960 to 110 million tons in 2000. This implies an increase in labor productivity from 0.26 to 1.1 million tons per thousand workers. ${ }^{11}$ Total material use tracks output quite closely, while labor and capital fall continuously over the entire period; which suggests that TFP had to increase to offset the sharp drop in labor and capital. ${ }^{12}$ Figure 1 clearly indicates that there are two very distinct periods during which TFP increased. The first period, 1972-1982, is characterized by a serve decline in output; whereas in the second period, 1987 onwards, total output started to increase again.

\section{[FIGURE 1 ABOUT HERE]}

\section{Fact 2: A New Production Technology: Minimills}

The entry of minimills in steel production constituted a drastic change in the actual production process of steel products. A natural question to ask is whether MM are any different than the traditional VI steel producers. We rely on a descriptive OLS regression in which we regress direct measurable characteristics on a dummy variable indicating whether a plant is a vertical integrated producer. We consider a log specification such that the coefficient on the technology dummy directly measures the percentage premium of VI plants in terms of the relevant characteristic. Table 3 lists the set of estimated coefficients.

\section{[TABLE 3 ABOUT HERE]}

\footnotetext{
${ }^{10}$ Shipments are deflated using 1987 USD and the producer price index for steel produced by the Bureau of Labor Statistics PCU331111331111. This change in shipments captures both changes in prices and output, and we decompose both components in detail later on. Appendix C.1 discusses deflators in more detail.

${ }^{11}$ Shipments of steel in tons are collected from various Iron and Steel Institute Annual Statistical Reports (American Iron and Steel Institute, 2010).

${ }^{12}$ Table 10 in Appendix B lists the growth in output and the various inputs for a five year period. For this aggregate analysis we rely on the NBER's five factor TFP estimate. See Bartelsman, Becker, and Gray (2000) for more detail.
} 
These regressions confirm that vertical integrated producers are on average four times bigger, as measured by the large coefficients on shipments, value added, and inputs. For example, VI plants on average ship 144 percent more. Moreover, VI producers generate about 20 percent more shipments per worker, which suggests that they are more productive. However, when we combine the coefficients on all three inputs (labor, materials and capital) with the shipment premium, we see that total factor productivity (TFP) of MM is at least as high as that of VI producers. In order to compare TFP across both types we need to estimate the production functions. We turn to this in section 4.

In addition to the average premium over the entire sample, we report the time specific coefficients. Across all the various characteristics the VI premium goes down. Most notably, shipments per worker are about 23 percent higher in 1963 and by the end of our sample, 2002 , there is no significant difference between the two technologies. This pattern suggests that VI and MM producers are becoming more alike in terms of size and performance, although VI producers are still producing at a larger scale.

The coefficients on the wage, as shown in the last row, confirm the well known fact that VI producers pay on average higher wages, confirming the impact of unionization; minimill workers typically being non unionized. ${ }^{13}$ It is interesting to note that the wage gap between both technology types closes over time.

An important difference between MM and VI producers is the set of products they manufacture. MM produce a somewhat different product mix than VI plants. As Figure 2 shows, in 1997 MM's accounted for 33\% of industry output, but $59 \%$ and $68 \%$ of shipments of steel ingots and hot-rolled bar, but only $15 \%$ and $14 \%$ of hot and cold rolled sheet. MM typically produce lower quality steel products, which are often thicker products, while VI plants produce higher quality products. However, the product mix accounted for by MM changes dramatically over the last 40 years. Figure 2 shows that in 1977 MM's produced $27 \%$ of steel ingots and $24 \%$ of hot-rolled bar. After the contraction of the steel industry as a whole from 1977 to 1982, MM's increased their share of these products to $40 \%$, and by $200281 \%$ of hot-rolled Bar is produced by MM's. In contrast, in 1997, only $15 \%$ and $14 \%$ of hot and cold rolled sheet are produced by MM's. ${ }^{14}$ Thus the market share of MM in the higher quality product segments, sheet products, was rather stable up to 1997, after which their market shares did increase substantially.

[FIGURE 2 ABOUT HERE]

\section{Fact 3: A Stable Product Mix over Time}

\footnotetext{
${ }^{13}$ See Hoerr (1988) and in particular page 16 for evidence of the role of unionization on wages for VI and MM producers.

${ }^{14}$ Giarratani, Gruver, and Jackson (2007) discuss the entry of Minimills into the production of sheet products around 1990.
} 
We now turn from the production side to changes in the product market for Steel. Table 4 shows the product mix of the steel industry. ${ }^{15}$ It is worth mentioning that over forty years the product mix for steel has barely changed. Hot-rolled sheet accounts for $23 \%$ of shipments in 1963 and $31 \%$ in 2002, and hot-rolled bar accounts for $23 \%$ of shipments in 1963 and $22 \%$ in 2002 . The fact that the steel industry's products have been unchanged is essential for our identification of productivity growth, as the industry's production process has changed far more than it's products. ${ }^{16}$

\section{[TABLE 4 ABOUT HERE]}

\section{Fact 4: Heterogeneous Price Trends Across Products}

While the product mix of steel producers has been relatively unchanged from 1963 to today, the prices for these products have dropped considerably, which is unsurprising given the large increases in TFP in the industry. Figure 3 presents the price index for steel provided by the BLS, as well as the price indices for the four main products, hot and cold rolled sheet, hot rolled bar and steel ingots which taken together represent $80 \%$ of shipments in $1997 . .^{17}$

Figure 3 shows that the prices of all steel products followed a very similar, and gradually increasing, pattern up to 1980 . But from 1982 to 2000, there is a 50\% drop in the real price of steel. This dramatic drop tells us that the quantity of steel shipments has been gradually increasing since the mid eighties as total shipments started to slowly rise (see panel 1 of Figure 1). ${ }^{18}$

\section{[FIGURE 3 ABOUT HERE]}

Second, when we decompose these price trends further, we find that the prices of hotrolled bars and steel ingots have fallen faster than the prices for hot and cold rolled sheet. Remembering that sheet steel is primarily produced by vertically integrated producers, it is interesting to note that prices for bar and ingot products fell by $10 \%$ more than those for sheet products in 1982-1984, precisely at the point minimills were increasing their share of

\footnotetext{
${ }^{15}$ We break down steel into various products, a) hot-rolled steel sheet (HRS), b) hot-rolled bar (HRB), c) cold-rolled sheet (CRS), d) ingots and shapes, e) pipe and tube (P \& T), f) Wire, g) cold-finished bars $(\mathrm{CFB})$, and $\mathrm{h}$ ) coke oven and blast furnace products (Blast). More details on these product categories can be found in the data appendix.

${ }^{16}$ The one product whose shipments fall notably over this period are steel ingots and semi-finished shapes (henceforth SISS). However, SISS is primarily used in rolling mills to produce steel sheet. Since the mid 1990 's with the development of slab casting technologies, steel is directly shaped into sheets at the mill.

${ }^{17}$ We have taken care to deflate these price indices by the GDP deflator to show price trends for Steel relative to the rest of the economy.

${ }^{18}$ External support to this claim can be found in the various annual reports of the American Iron and Steel Institute (American Iron and Steel Institute, 2010) where total ton of steel are recorded annually. In this data, quantity produced increased by about thirty percent between 1982 and 2002 .
} 
sheet and bar products. This suggests that we have to correct for price differences across products, and hence producers, in order to avoid the omitted price bias when estimating the production function. ${ }^{19}$

\section{Fact 5: Simultaneous Entry and Exit}

From Figure 1 we know that the number of plants increased over time. In Table 5 we go a step further and document not only the number of MM and VI plants that entered or exited, but also the market share represented by these plants. There is marked entry of new plants in the early eighties, a period where the entire industry as a whole was severely contracting, and a large number of plants, especially VI plants, exited in this period. The market share of entrants from 1982 to 1992 is 20 percent, versus 5 percent in the previous two decades. This fact requires a more careful analysis of the underlying heterogeneity across producers. This phenomena, the speeding up of exit and entry during a downturn, has been documented by Bresnahan and Raff (1991) in the motor vehicles industry during the Great Depression. From these entry and exit statistics and substantial changes in their corresponding market shares, we expect an important role for entry and exit in explaining productivity growth, particularly since the net entry process affected a substantial part of the total market.

[TABLE 5 ABOUT HERE]

\section{Drivers of productivity growth}

The previous section discussed the difference in performance between both types of technology. This implies that there is a large potential role for reallocation across technology types to explain productivity growth. This paper is precisely concerned with studying the productivity differences in greater detail and verifying to what extent the entry of minimills contributed to stark aggregate productivity growth in the industry.

First, we start out by presenting our empirical framework. Second, we rely on our productivity estimates to verify the importance of reallocation, both across and within technology, in productivity growth. We consider both static and dynamic decompositions and therefore we can verify the importance of entry and exit in productivity growth, again by technology type. Our setting is particularly suited to study the role of entry and exit since our data covers forty years, 1963-2002, and therefore we can verify the long run effects of entry. Finally, we relate a direct measure of competition, markups, to the reallocation analysis by connecting markups to the covariance of market share and productivity.

\footnotetext{
${ }^{19}$ See Klette and Griliches (1996) and De Loecker (2011) for more on this.
} 


\subsection{Productivity Differences Across Technology}

We consider two distinct types of technology, $\psi \in\{V I, M M\}$, which correspond to vertical integrated and minimill producers, respectively. A plant $i$ at time $t$ can produce a unit of output $Q_{i t}$ using a technology-type $(\psi)$ specific production technology:

$$
Q_{i t}=F_{\psi, t}\left(L_{i t}, M_{i t}, K_{i t}\right) \exp \left(\omega_{i t}\right)
$$

Our notation highlights that VI and MM producers rely on different technologies, which we allow to vary over time. We take a standard view of productivity $\left(\omega_{i t}\right)$ and model it as a Hicks-neutral term. Equation (1) encompasses different factor shares, allowing for differences in capital-labor intensities.

We start by considering a few baseline specifications for the standard Cobb-Douglas production function. Table 6 presents estimates of the production function. Columns I, II and III show results with output defined as sales deflated by a common price deflator, while Columns IV, V, and VI show estimates using output deflated by product specific prices, which corrects output for a plant's specific product mix. ${ }^{20}$ Columns I, II, VI, and V compute OLS estimates, while Columns III and VI (GMM) present investment control function estimates of productivity (Ackerberg, Benkard, Berry, and Pakes, 2007) discussed in further detail in Appendix C.2.

\section{[TABLE 6 ABOUT HERE]}

The production function coefficients, across all specifications, are stable and have reasonable estimates of returns to scale and output elasticities. An important test for our purpose is to check whether minimills and vertical integrated producers rely on different input factor shares. In order to test this we simply interact every coefficient with our technology type dummy and run a F-test on the joint significance of the interacted coefficients. In doing so, we cannot reject that both technologies produce under the same output elasticities of labor, materials, and capital. Four main results emerge from this analysis. ${ }^{21}$

First, minimills are on average more productive as indicated by a negative coefficient on the VI dummy. Under specification I minimills have on average a 5 percent higher TFP than vertically integrated producers. This result restates our findings in Table 2 where the gap in output between both technology types was shown to be smaller than the gap in input

\footnotetext{
${ }^{20}$ Appendix C.1 discusses the construction of these deflators in more detail.

${ }^{21}$ At first it might seem surprising that for instance the coefficient on materials does not vary across technologies. However, note that this coefficient reflects the importance of the total use of intermediate inputs in final production. Aggregating over the various intermediate inputs into $M_{i t}$ masks the distinct inputs used in production which differ tremendously by technology. For instance, in 2002, Iron and Steel Scrap represents $42 \%$ of the coded material inputs for minimills, and Coal for the production of Coke represents $15 \%$ of the coded material inputs for vertically integrated plants.
} 
use. The results in Table 6 are obtained however by weighing the various inputs by their estimated output elasticities. ${ }^{22}$

Second, the TFP premium for minimills decreases over time as indicated by the positive coefficient of $0.3 \%$ on the technology-year. Although this coefficient is relatively small in magnitude, one has to keep in mind that our sample is about 40 years, which implies that by the end of our sample the TFP premium for MMs has disappeared. This will be important to keep in mind as we compute our decompositions, i.e. we expect the impact of minimills in aggregate productivity growth to be concentrated at the beginning of the sample.

Third, the results in Panel B demonstrate the importance of controlling for unobserved prices in the revenue generating production function (Panel A) and confirms the findings of De Loecker (2011). In particular, when we correct for product specific prices we find that the minimill TFP premium is twice as high. The impact of including detailed price data on the technology coefficient is as expected since we know from Figure 3 that VI plants are active in the relatively higher quality segments where producer prices are higher. Therefore when we do not properly deflate the sales data the productivity premium for minimills is dampened. ${ }^{23}$

Fourth, the common biases in the estimation of production functions understate the productivity advantages of minimills. Attenuation bias lowers the estimated returns to scale. Since VI plants are larger than minimills, this will make VI plants look more productive than they really are. Likewise, simultaneity typically results in downward bias on the capital coefficient. Since VI plants are more capital intensive than minimills, this will again make VI plants appear more productive. When we correct for the simultaneity and selection biases in Columns III and VI using an investment control function correction, the capital coefficient is twice as large. Moreover, the minimill TFP premium doubles to an average effect of 11 percent, starting at 25 percent in 1963, but disappearing by 2002 .

In all the subsequent analysis we rely on estimates of productivity, $\omega_{i t}$ from Column VI of Table 6. It is interesting to note that the standard deviation of $\omega_{i t}$ hovers around 30 percent over the sample, and thus while differences in technology account for an 11 percent gap in productivity, there remain substantial productivity differences between producers.

\subsection{The Role of Reallocation}

Following Olley and Pakes (1996) we consider industry-wide aggregate productivity as the market share, denoted by $s_{i t}$, weighted average of productivity $\omega_{i t} .{ }^{24}$ In particular we rely

\footnotetext{
${ }^{22}$ To put these TFP premiums into perspective, an 10 percent increase in TFP raises the rate of return on capital by 15 percentage points, given the output to capital ratio in the industry.

${ }^{23}$ Taking the results across both panels $\mathrm{A}$ and $\mathrm{B}$ together also suggests that the markups of minimills are expected to be higher since they still operate at lower marginal costs, due to higher productivity, as we control for prices.

${ }^{24}$ In our analysis we also rely on alternative measures for the plant-level weights such as inputs into production For example, we also compute aggregate productivity using labor input (measured in hours
} 
on the following definition of aggregate productivity $\Omega_{t} \equiv \sum_{i} s_{i t} \omega_{i t}$.

\subsubsection{Static Analysis}

In recent work, Bartelsman, Haltiwanger, and Scarpetta (2009) discuss the usefulness of the Olley and Pakes decomposition methodology. They highlight that the positive covariance between firm size and productivity is a robust prediction of recent models of producer-level heterogeneity (in productivity), such as Melitz (2003). We follow the standard decomposition of this aggregate productivity term (also referred to as the OP decomposition) into unweighted average productivity and the covariance between productivity and market share, or:

$$
\Omega_{t}=\bar{\omega}_{t}+\sum_{i}\left(\omega_{i t}-\bar{\omega}_{t}\right)\left(s_{i t}-\bar{s}_{t}\right)
$$

The same decomposition can be applied by technology type $\psi$ and this particular decomposition will help us understand whether average productivity of the different technology types evolved differently, and whether there is any substantial reallocation across producers of the same vintage. We call this the within decomposition. In order to verify the importance of the $\psi$ specific components in the total productivity aggregate, $\Omega_{t}$, we need to weigh the type specific aggregates, $\Omega(\psi)$, by their respective market shares. Denote the average productivity within a technology type $\psi$ as $\bar{\omega}_{t}(\psi)$, and the average market share of plants within a technology type $\psi$ as $\bar{s}_{t}(\psi) .{ }^{25}$ In terms of our decomposition we can therefore write the aggregate productivity as follows:

$$
\Omega_{t}=\sum_{\psi} s_{t}(\psi)\left(\bar{\omega}_{t}(\psi)+\sum_{i \in \psi}\left(\omega_{i t}-\bar{\omega}_{t}(\psi)\right)\left(s_{i t}(\psi)-\bar{s}_{t}(\psi)\right)\right)
$$

This within decomposition reflects both the change in the actual type specific component, the unweighted average and the covariance term, as well as the type specific market share. ${ }^{26}$

To measure the importance of reallocation of resources between technologies we interact the productivity index with the type specific market share, $s_{t}(\psi)$. We apply the same type of decomposition but now the unit of observation is a type, hence two data points per time period, which allows us to isolate the between type reallocation component in aggregate productivity using:

$$
\Omega_{t}=\bar{\Omega}_{t}(\psi)+\operatorname{cov}_{t}\left(s_{t}(\psi), \Omega_{t}(\psi)\right)
$$

worked or employment) as a weights. See De Loecker and Konings (2006) for such an analysis in the context of relating job flows to productivity during the transition process in Central and Eastern Europe.

${ }^{25}$ The OP-decomposition relies crucially on the property that the market shares sum to one. However, if we were to simply split the summation across the two types we could not isolate the within covariance term. To see this, note that $\sum_{\psi} \Omega_{t}(\psi) \neq \Omega_{t}$, due to the fact that $\sum_{\psi, i} s_{i t}(\psi)>1$.

${ }^{26}$ However, to asses the productivity effects within a type this rescaling by the type specific market share has no effect. 
where $s_{t}(\psi)=\sum_{i \in \psi} s_{i t}$ and the second term is the covariance measuring the extent to which the resource reallocation towards minimills contributed to the aggregate productivity term defined before. It is important to underscore that the average market share is always equal to one half, and when market shares are equal across the two types, the reallocation component as measured by the covariance term is zero independent of the productivity differences between the two types. ${ }^{27}$ Note that the between average component, overline $\Omega_{t}(\psi)$, can itself directly be decomposed into the within and covariance component by type, i.e. four different components. ${ }^{28}$

Table 7 shows the various cross-sectional decompositions of aggregate productivity. Panel A shows the standard Olley-Pakes decomposition across all plants, and the between technology decomposition. In Panel B we present the decompositions by technology.

\section{[TABLE 7 ABOUT HERE]}

Four important results emerge. First, the OP decomposition of aggregate productivity across all plants, shows the average producer became 15.5 percent more productive between 1963 and 2002. In addition, the reallocation towards more productive plants was an important process in generating higher productivity, generating a 7.5 percent increase from 1963 to $2002 .{ }^{29}$ Thus aggregate productivity went up by 23 percent, of which 33 percent was due to the reallocation towards more productive plants. This indicates that reshuffling of market shares across producers was an important mechanism through which the industry realized productivity gains.

Second, the increase in productivity occurs primarily from 1972 to 1977 where TFP rises by about 10 percent, and from 1992 to 2002 where productivity increased by another 13 percent. Interestingly, these two episodes of productivity growth are driven by very different mechanisms. The productivity increase from 1992 to 1997 is almost entirely due to the increase in productivity by the average plant $\bar{\omega}_{t}$. However, the increase from 1972 to 1977, a period characterized by a fall in demand, is driven by a relatively high covariance term (of about 60 percent in the 1972-1977 productivity growth). These results therefore suggest that reallocation plays a large role during a contraction in demand but not as much during the recovery of demand. ${ }^{30}$

\footnotetext{
${ }^{27}$ Given the substantial entry of minimills who typically entered at a smaller scale, and remain smaller, we can expect the covariance term to be negative, i.e. the more productive plants have a smaller market share. But we do expect this covariance term to become less negative over time, as Figure 2 shows that minimills started with a very small market share and gradually captured a larger part of the market.

${ }^{28}$ Specifically, in presenting the results we use the fact that $\bar{\Omega}_{t}(\psi)=0.5 *$ $\sum_{\psi}\left(\bar{\omega}_{t}(\psi)+\sum_{i \in \psi}\left(\omega_{i t}-\bar{\omega}_{t}(\psi)\right)\left(s_{i t}(\psi)-\bar{s}_{t}(\psi)\right)\right)$, and this allows us to decompose the between average component into four subcomponents, the within and covariance term by technology type.

${ }^{29}$ Note that all the numbers are kept in logs as opposed to the original OP approach where an index was created since productivity was expressed in dollars.

${ }^{30}$ We revisit the relationship between the covariance term and demand for steel in section 4.3.
} 
Third, drilling down to the technology type in Panel B, we see that the reallocation among the incubment technology (16 percent) and the unweighted productivity growth of minimills (21 percent) are, perhaps surprising, equally important in explaining the change in aggregate productivity (shown in the Share Overall row). The time trajectory of productivity growth for minimills does reveal that periods of strong productivity growth coincide with minimillw breaking into new product segments, as shown in Figure 2, suggesting that minimills were learning slowly to produce higher quality steel products. The vertical integrated producers on the other hand were less productive than the minimills, but by the end of the sample period almost completely caught up. The decomposition for the VI, however, does provide a very different picture: the large reallocation among VI took place right when the minimills entered; whereas the sharp increase in VI's productivity in the last decade, 1992-2002, was largely due to the increase of the unweighted average.

Fourth, we present the results of the between technology decomposition, in the last three columns of Panel A, which relies on the aggregate productivity indices by technology, as well as the market share evolution of both technologies in total steel production. The decomposition suggest that the sources of productivity growth in the U.S. steel industry differ quite a bit over the sample period. During the first part of the sample period, 1962-1982, a large part of the improvement in the performance of the overall industry came from the rise of the minimills which were on average about 15 percent more productive. ${ }^{31}$ The second half of the sample, 1982-2002, is characterized by a sharp increase of productivity of the (remaining) vertical integrated producers. We see that the between technology reallocation component is as expected, i.e. at first it is negative because the older vintage of VI plants have both lower productivity and greater market share. It then becomes less negative as the minimills, who have productivity premium, take over 25 percent of market share. Towards the end of the sample minimills have about half of the market which mechanically implies a zero between reallocation component. This between reallocation of output from VI plants to MM's accounts for 27 percent of the overall productivity growth of the industry. The fact that production technology can account for changes in the covariance term is critical, since this suggests an important role for technology in explaining the reallocation that lead to a sharp increase in productivity.

\subsubsection{Dynamics: the role of entry and exit}

The above decomposition masks the potential impact of entry and exit on aggregate productivity. In other words, the covariance term can change over time due reallocation across incumbents and or due entry and exit. We turn to this and consider a dynamic version of

\footnotetext{
${ }^{31}$ It is worth mentioning that when plotting (deflated) value added per worker by technology a very similar picture emerges for the minimills and the integrated producers. However, once we control for the capital stock (and the appropriate weights on the variable inputs) the productivity premium for minimills is substantial, ranging about ten percent up to the year 1992 after which integrated producers catch up to the minimill productivity level.
} 
our decomposition. Let us consider three distinct sets of producers for a given time window $t-1, t$, where $t$ is a 10 year window: incumbents $(A)$, entrants $(B)$ and exiting plants $(C) .{ }^{32}$. Using these sets, use equation (2) and consider aggregate productivity growth:

$$
\begin{aligned}
\Delta \Omega_{t}= & \underbrace{\sum_{i \in A} s_{i t-1} \Delta \omega_{i t}}_{\text {Within }}+\underbrace{\sum_{i \in A} \Delta s_{i t} \omega_{i t-1}}_{\text {Between }}+\underbrace{\sum_{i \in A} \Delta s_{i t} \Delta \omega_{i t}}_{\text {Cross }} \\
& +\underbrace{\sum_{i \in B} s_{i t} \omega_{i t}}_{\text {Entrant }}-\underbrace{\sum_{i \in C} s_{i t-1} \omega_{i t-1}}_{\text {Exit }}
\end{aligned}
$$

where we group the first three terms on the RHS as the Within, Between and, Cross terms, and the last two terms as the Entry and Exit components. The above decomposition directly isolates the net-entry effect on aggregate productivity by verifying the importance of the last two components in total productivity growth. Finally, to isolate the role of entry and exit for both types of technology separately we expand the above by computing equation (5) by technology type $\psi$. When we refer to the total impact of reallocation we group the last four terms.

Table 8 presents the decomposition across all plants and by technology. The change in $\Omega_{t}$ is computed over the entire sample period 1963-2002. ${ }^{33}$

\section{[TABLE 8 AROUND HERE]}

The first row of Table 8 restates the large productivity growth in the US steel sector. ${ }^{34}$ Across the entire sample period the results point out the large role of entry and exit across all plants, i.e. about 19 percent of aggregate productivity growth was due to the simultaneous entry and exit of plants. The total share of reallocation in aggregate productivity growth, including both the reallocation induced by market share reallocation across incumbents and the net entry process, is 66 percent.

A clear picture emerges when we move to the decomposition by technology. The main driver of productivity growth for minimills is the within component capturing the technological change of minimills. This is suggestive of the substantial learning by doing that took place in minimill production, in particular learning how to produce higher quality steel. For integrated producers the story is very different. The net entry term is about 19 percent of total productivity growth over the sample. Panel B of Table 8 restates the distinct role of the net-entry process across technologies. We present the productivity premium of entrants, compared to the set of exiting plants, and we do this for different time periods, as well as

\footnotetext{
${ }^{32}$ This decomposition has been suggested by Davis, Haltiwanger, and Schuh (1996) and has been used in other empirical work by e.g. De Loecker and Konings (2006).

${ }^{33}$ We also analyzed the changes over a ten year period. Due to census disclosure rules we would not be able to present for shorter time windows, and the results are very similar.

${ }^{34}$ The numbers on the minimill and integrated need to be scaled by their relevant market share changes using $\Omega_{t}=\sum_{\psi} s_{t-1}(\psi) \Omega_{t}(\psi)+\Delta s_{t}(\psi) \Omega_{t-1}(\psi)+\Delta s_{t}(\psi) \Delta \Omega_{t}(\psi)$.
} 
over the entire sample period. ${ }^{35}$ Across the entire sample period, VI entrants are 4.4 percent more productive than those VI plants that exited the industry. New minimills, on the other hand, enter with no specific productivity advantage.

To summarize the importance of reallocation, we collect all the terms that reflect reallocation of resources, the last row in Panel A, we find a drastic difference between both technologies. Whereas the productivity growth of minimills isentirely due to common withinplant productivity growth, integrated producers' productivity growth is mainly coming from the reallocation of resources across producers ( 67 percent), and about one third of this reallocation comes from the entry and exit process.

\subsection{Market Power and Reallocation}

We rely on our production function framework to recover markups by technology type and plant. In order to obtain markups from the plant-level production data we follow the approach suggested by De Loecker and Warzynski (forthcoming) and we refer to the appendix for the details of that approach.

At the core of this approach lies the assumption that plants minimize costs and that at least one input of production faces no adjustment costs. Taking these two assumptions together and relying on the production function in equation (2) gives rise to the following expression for the markup:

$$
\mu_{i t}=\theta_{i t}^{M}\left(\alpha_{i t}^{M}\right)^{-1}
$$

where $\theta_{i t}^{M}$ is the output elasticity of (variable) input, materials $(M)$, and $\alpha_{i t}^{M}$ is the share of expenditures on materials in total sales of the plant. We refer the reader to De Loecker and Warzynski (forthcoming) for more details on how to compute markups. The two main ingredients into computing markups are the output elasticity of intermediate inputs, such as materials and energy, and the corresponding expenditure share of the input. The latter are directly observed in the data, whereas the output elasticities are recovered after we estimate the production function as discussed above. ${ }^{36}$

To compare markups across the two types, we consider a weighted average by type, and we can now apply the same decomposition as we did for productivity to investigate whether the markup change over time was mostly due a common change in markups, i.e. an industry wide decrease in concentration, or whether markups of relatively high market share plants declined more. ${ }^{37}$

\footnotetext{
${ }^{35}$ In terms of equation (5) we simply compare the last two terms.

${ }^{36}$ In our context the output elasticities are obtained by relying on product specific price deflators, and potentially leave plant-level price variation left uncontrolled for. The latter is expected to bias the output elasticity downward and therefore downward bias the level of the markup. Under a Cobb-Douglas production technology this has no implication on the time series pattern of markups and on the comparison of markups across minimills and integrated producers. As long as the output elasticity is fixed across types.

${ }^{37}$ As discussed in De Loecker and Warzynski (forthcoming) if sales and input expenditures are only available at the plant level, we can interpret the markup as weighted average of product-level markups where the weights are the unobserved product-specific expenditure shares.
} 
We compute markups by technology as obtained from technology specific aggregate expenditures on an intermediate input $\left(E_{t}(\psi)\right)$, materials in our case, and sales $\left(R_{t}(\psi)\right)$ while relying on a time invariant Cobb-Douglas output elasticity of the intermediate input $\left(\beta_{m}\right){ }^{38}$ In particular we rely on the following expression to compute these aggregate markups by technology type:

$$
\mu_{t}(\psi)=\beta_{m} \frac{R_{t}(\psi)}{E_{t}(\psi)}
$$

Figure 4 plots the markup trajectory over 40 years for both MM and VI plants. Markups have steadily decreased over time and are consistent with the drop in prices and external measures of concentration reported for the steel sector. ${ }^{39}$ Markups are on average higher for minimills, confirming the results from the augmented production function estimation in Table 6.

\section{[FIGURE 4 ABOUT HERE]}

It is interesting to note that markups fall at the same time as the covariance between output and productivity increases. Suppose that this fall in markups is due to firm's residual demand curve becoming more elastic. In other words, markups fall because the product market for steel becomes more competitive. This does not seem unlikely since import competition has risen from 5 to over 40 percent of domestic consumption, and there are far more steel producers in 2002 than 1963. Then using the model outlined in Appendix D which assumes a CES residual demand curve and a lognormal distribution for productivity, a more elastic residual demand curve leads to lower markups and a higher covariance between output and productivity. This relationship is likely to be quite general, as a more elastic residual demand curve will accentuate the relationship between productivity and output. Thus we expect the extent of competition to be directly linked to reallocation, which is what we find in the data.

\subsection{Collecting Our Results}

We find that the diffusion of minimills has a large impact on the steel industry. First, minimills diffuse slowly throughout the industry. In 1963 they represent less than 5 percent of the industry's output, rising to over 40 percent in 2002. However, this diffusion differs

\footnotetext{
${ }^{38} \mathrm{We}$ are currently in the process of generating plant and time specific markup estimates using a translog production function with time varying output elasticities as proposed and found important by De Loecker and Warzynski (forthcoming). However, under the commonly assumed Cobb-Douglas production function these markups are in fact the correct technology specific markups, where the markup by technology can be thought of as a weighted average across plants where the weights are the expenditure share on materials of a given plant in the total expenditure for plants of the same technology.

${ }^{39}$ The trajectory of markups in itself warrants attention and has been at the core of outstanding debate on the role of monetary policy and whether markups are pro or countercyclical. We see this as important by-product of our setting and approach.
} 
by product segment, as minimills produce 60 percent of bar products in 1990, but only 15 percent of sheet products.

Second, we find that minimills are substantially more productive than vertically integrated plants. This difference in productivity is masked by price changes, since the products produced by minimills, which are primarily bar products, have prices that fall by about 10 percent more than the prices of products produced by vertically integrated producers (mainly bar and sheet products). These price changes are enormous, as the 30 percent increase in productivity in the industry is concurrent with a 40 percent fall in prices for steel products.

Third, reallocation, either on the intensive margin or the extensive margin of entry and exit, explains a large share of productivity growth in this industry from 1963 to 2002 . However, reallocation has vastly different effects for minimills and vertically integrated plants. Indeed, reallocation plays no role in the productivity growth of minimills, while for vertically integrated plants, reallocation is responsible for over 65 percent of it. The mechanisms of reallocation are more important in the more established and contracting segment of the industry. This process of creative destruction is quite visible as both exit and entry are much more important during the 50 percent fall in demand that hit the industry in the early 1980s than at any other period. Overall, the entry of minimills is directly reponsible for 50 percent of the productivity growth of the industry at large. However, the remaining productivity growth, due to improvements of integrated producers, can at least, partially, be attributed to minimills as well. To the extent that increased competition, as measured by an increase of minimills market shares across the various product segments, lead integrated producers to invest in new production technologies and improve their overall efficiency, the entry of a new technology can be responsible for almost all of the productivity improvements. Of course, we do not claim that all of the integrated producers' productivity gains are due to the minimill entry. We defer this discussion to the next section.

Fourth, the industry has periods with a negative covariance between output and productivity. This pattern is difficult to explain, since almost any model would predict that more efficient plants would grow more than less efficient ones. However in steel, the old technology of vertically integrated plants has a much larger minimum efficient scale, and these plants are on average four times larger than minimills. Thus the observed negative covariance is due to the fact that vertically integrated producers are both bigger and less productive than minimills.

Finally, we find markups fall from about 1.3 in 1967 to around 1 in 2002 . As these markups are tightly linked to the elasticity of the residual demand curve, we see falling markups as evidence of increases in competition in the industry which lead to increases in reallocation. 


\section{Discussion and Caveats}

While we have extensively documented the large growth of productivity in the steel industry due to the entry of minimills, there is a substantial, 50 percent, role played by the integrated producers. We discuss the slow speed of reallocation towards minimills, the role of international trade, and technological changes which drove the catch up of VI plants to MMs.

\subsection{Incomplete Reallocation}

Given the substantial productivity advantages of minimills a natural question is why did they not take over the entire industry.

When we drill down to the specific product level, we find that minimills did take over the bar product segment, but not the sheet segments. The reason for this is technological, as minimills have only recently been able to produce sheet products. ${ }^{40}$

As well, there are large capital costs of building a vertically integrated plant, as the average VI plant has building and machinery assets of over half a billion dollars. This capital is almost entirely sunk. Thus while a VI producer might be inefficient from an ex-ante perspective, it is profitable for a VI plant to continue production once it has been built. ${ }^{41}$

The 15 percent productivity advantages of minimills coexists with a large dispersion in productivity within both VI and MM producers. Indeed, the standard deviation of productivity across all plants is about 30 percent. Therefore it is far from the case that every minimill is more productive than every VI producer, and thus even in the absence of any reallocative frictions we would not see minimills completely take over the industry.

Finally, our results suggests that even a full reallocation towards minimills, keeping their productivity premium fixed, would only lead to about 66 percent of the actual productivity growth we see in the data. ${ }^{42}$ The latter confirms that there is a separate and important role for integrated producers in explaining productivity growth.

\subsection{International Trade}

We have not addressed the issue of international trade which clearly has a large role for this industry. From 1963 to 2002 import penetration increased from 5 to 30 percent, and export

\footnotetext{
${ }^{40}$ Indeed, as documented by Oster (1982), the previous generation of steel production in open hearth furnace was rapidly displaced by the basic oxygen furnace. In contrast to minimills, basic oxygen furnaces were complete substitutes for open hearth furnaces.

${ }^{41}$ See Collard-Wexler (2009) for a fully worked out version of the importance of sunk costs in shaping productivity dispersion in the ready-mix concrete industry. Note that the majority of VI production takes place at plants built prior to 1963.

${ }^{42}$ This simple calculation is used to highlight the potential impact of a full reallocation, clearly with the caveat in mind that we keep all else fixed. To obtain the 66 percent share, we rely on the 1963 productivity premium inferred from Table 7 as follows: $(0.044+0.107) / 0.23$.
} 
penetration went up from 3 to 7 percent. ${ }^{43}$ However it is difficult to know what productivity growth would have been in the absence of this increase in international trade in the absence of a better model of productivity growth.

When we break down imports and exports by product we find that imports show a similar rise for bar products produced by minimills as for the sheet products which minimills do not produce. Thus it is not possible for us to identify a differential role of international competition on the reallocation from VI to MMs.

However, the large increase in the importance of international trade may provide a reason for the sharp in markups documented in Figure 4, as has been discussed by Blonigen, Liebman, Pierce, and Wilson (2010). As the importance of international competition increases, we might expect a firm's residual demand curve to become more elastic. We leave this investigation for future research.

\subsection{Improvements at VI Plants}

A notable fact is the catch-up in productivity of VI producers to minimills. Indeed, while minimills have a 17.2 percent productivity advantage over VI producers in 1963, this advantage almost completely disappears by 2002 to about 3.6 percent. ${ }^{44}$ We were able to identify a distinct role of the exit process of inefficient incumbent producers, leading to about 20 percent of the VI productivity improvements. The reallocation among surviving VI producers together with this net entry process captures 67 percent, leaving 33 percent for pure technological change of the VI producers. We have not identified the underlying source for this component and leave this for future research.

\section{Conclusion}

There is extensive evidence that large gains in productivity can be attributed to reallocation of resources towards more productive plants. This paper shows the role of technology and competition in the reallocation process for the American Steel industry.

We provide direct evidence that technological change can itself bring about a process of resource reallocation over a long period of time and lead to substantial productivity growth for the industry as a whole. More specifically, we find that the introduction of a new production technology spurred productivity growth through two channels.

First, the entry of minimills lead to a slow but steady drop in the market share of the incumbent technology, the vertically integrated producers. As minimills were 11 percent

\footnotetext{
${ }^{43}$ These statistics are sourced from various issues of the American Iron and Steel Institute Annual Report (American Iron and Steel Institute, 2010). We report import and export shares as the percent of total tons of steel consumed domestically.

${ }^{44}$ Using Table 7 we compute the productivity premium by comparing the aggregate productivity columns by type, for the year 1963 for instance: $0.044+0.128=0.172$.
} 
more productive, this movement of market share between technologies is responsible for a third of productivity growth in the industry.

Second, while the new technology started out with a 25 percent productivity premium, by the end of the sample, minimills and vertically integrated producers are very similar in terms of efficiency. This catching-up process of the incumbents came about from a large within reallocation of resources among vertically integrated plants. On the other hand, minimills productivity grew moderately, and almost entirely because of a common shift in the production frontier.

As as consequence of productivity growth, prices for steel products fell rapidly, though at different rates for those products which minimills could produce, versus those they could not. Markups decreased substantially, reflecting that prices fell more rapidly than production costs. This indicates increased competition for U.S. steel producers, which further drove increases in productivity. 


\section{References}

Ackerberg, D., L. Benkard, S. Berry, and A. Pakes (2007): "Econometric Tools for Analyzing Market Outcomes," in Handbook of Econometrics, ed. by J. Heckman, and E. Leamer, vol. 6a, chap. 63, pp. 4171-4276. Elsevier.

Ackerberg, D., G. Frazer, and K. Caves (2006): "Structural Estimation of Production Function," Working Paper UCLA.

American Iron and Steel Institute (2010): Annual Statistical Report of the American Iron and Steel Institute. Washington D.C.

Asker, J., A. Collard-Wexler, and J. De Loecker (2012): "Productivity Volatility and the Misallocation of Resources in Developing Economies," Working Paper NYU.

Bartelsman, E., R. Becker, and W. Gray (2000): "Nber-ces manufacturing industry database," Last accessed May, 25, 2006.

Bartelsman, E., J. Haltiwanger, and S. Scarpetta (2009): "Cross-country differences in productivity: the role of allocation and selection," Discussion paper, NBER Working Paper.

Blonigen, B., B. Liebman, J. Pierce, and W. Wilson (2010): "Are All Trade Protection Policies Created Equal? Empirical Evidence for Nonequivalent Market Power Effects of Tariffs and Quotas," Discussion paper, National Bureau of Economic Research.

Bloom, N., B. Eifert, A. Mahajan, D. McKenzie, and J. Roberts (2011): "Does management matter? Evidence from India," Discussion paper, National Bureau of Economic Research.

Bresnahan, T. F., and D. M. G. RafF (1991): "Intra-Industry Heterogeneity and the Great Depression: The American Motor Vehicles Industry, 1929-1935," The Journal of Economic History, 51(2), 317-331.

Collard-Wexler, A. (2009): "Productivity Dispersion and Plant Selection in the ReadyMix Concrete Industry," Working Paper, New York University.

Crandall, R. (1981): The US steel industry in recurrent crisis: policy options in a competitive world. Brookings Institution Press.

Davis, S. J., J. C. Haltiwanger, and S. Schuh (1996): Job creation and destruction. MIT Press Cambridge, Mass.

De Loecker, J. (2011): "Product Differentiation, Multiproduct Firms, and Estimating the Impact of Trade Liberalization on Productivity," Econometrica, 79(5), 1407-1451.

De Loecker, J., And J. Konings (2006): "Job reallocation and productivity growth in a post-socialist economy: Evidence from Slovenian manufacturing," European Journal of Political Economy, 22(2), 388-408.

De Loecker, J., and F. Warzynski (forthcoming): "Markups and firm-level export status," American Economic Review. 
Foster, L., J. Haltiwanger, and C. Krizan (2001): "Aggregate productivity growth. Lessons from microeconomic evidence," .

Fruehan, R. (1998): The Making, Shaping and Treating of Steel - 11th Edition. AISE Steel Foundation, Pittsburgh, USA.

Giarratani, F., G. Gruver, and R. Jackson (2007): "Clusters, agglomeration, and economic development potential: empirical evidence based on the advent of slab casting by US steel minimills," Economic Development Quarterly, 21(2), 148-164.

HaLl, C. (1997): Steel phoenix: The fall and rise of the US steel industry. Palgrave Macmillan.

Hoerr, J. (1988): And the wolf finally came: The decline of the American steel industry. University of Pittsburgh Press Pittsburgh.

Hortaçsu, A., And C. Syverson (2004): "Cementing Relationships: Vertical Integration, Foreclosure, Productivity, and Prices," .

Jarmin, R., S. Klimek, and J. Miranda (2009): "The Role of Retail Chains: National, Regional and Industry Results," .

Klette, T., And Z. Griliches (1996): "The inconsistency of common scale estimators when output prices are unobserved and endogenous," Journal of Applied Econometrics, $11,343-361$.

Olley, G. S., And A. Pakes (1996): "The dynamics of productivity in the telecommunications equipment industry," Econometrica, 64(6), 35.

Oster, S. (1982): "The Diffusion of Innovation among Steel Firms: The Basic Oxygen Furnace," The Bell Journal of Economics, 13(1), pp. 45-56.

Rogers, R. (2009): An economic history of the American steel industry. Taylor \& Francis.

Schmitz, J. (2005): "What determines productivity? Lessons from the dramatic recovery of the US and Canadian iron ore industries following their early 1980s crisis," Journal of Political Economy, 113(3), 582-625. 


\section{TABLES AND FIGURES}

Table 1: Relative Performance of the steel sector

\begin{tabular}{cccc}
\hline \hline Sector & $\Delta$ TFP & $\Delta$ Shipments & $\Delta$ Labor \\
\hline Steel Sector & $28 \%$ & $-35 \%$ & $-80 \%$ \\
Mean Sector & $7 \%$ & $60 \%$ & $-5 \%$ \\
Median Sector & $3 \%$ & $61 \%$ & $-1 \%$ \\
\hline \hline
\end{tabular}

Source: NBER-CES Dataset for SIC Code 3312. Note: Only sectors over 10 billion dollars are included. Changes computed between 1972-2002.

Table 2: Summary Statistics for Minimills and Vertically Integrated Producers $\underline{\text { Vertically Integrated }}$

\begin{tabular}{lrrr}
\cline { 1 - 3 } Shipments $\dagger$ & Mean & Std. Dev. & Observations \\
Value Added $\dagger$ & 647 & 671 & 2,192 \\
Cost of Materials $\dagger$ & 261 & 311 & 2,192 \\
Investment $\dagger$ & 343 & 369 & 2,192 \\
Assets $\dagger$ & 36 & 63 & 2,192 \\
Workers & 690 & 860 & 1,525 \\
Wage Per Hour & 3,062 & 3,721 & 2,192 \\
& 25 & 8 & 2,192 \\
Minimills & & & \\
& & & \\
Shipments $\dagger$ & Mean & Std. Dev. & Observations \\
Value Added $\dagger$ & 153 & 178 & 2,687 \\
Cost of Materials $\dagger$ & 61 & 80 & 2,687 \\
Investment $\dagger$ & 85 & 112 & 2,687 \\
Assets $\dagger$ & 7 & 17 & 2,687 \\
Workers & 103 & 139 & 1,705 \\
Wage Per Hour & 633 & 750 & 2,687 \\
& 25 & 9 & 2,687
\end{tabular}

Note: † In millions of 1997 dollars. The number of observations for total assets is smaller since these are not part of the ASM after 1992. 
Table 3: Differences between Minimills and Vertically Integrated Plants Plant-level characteristic Premium for VI Plants

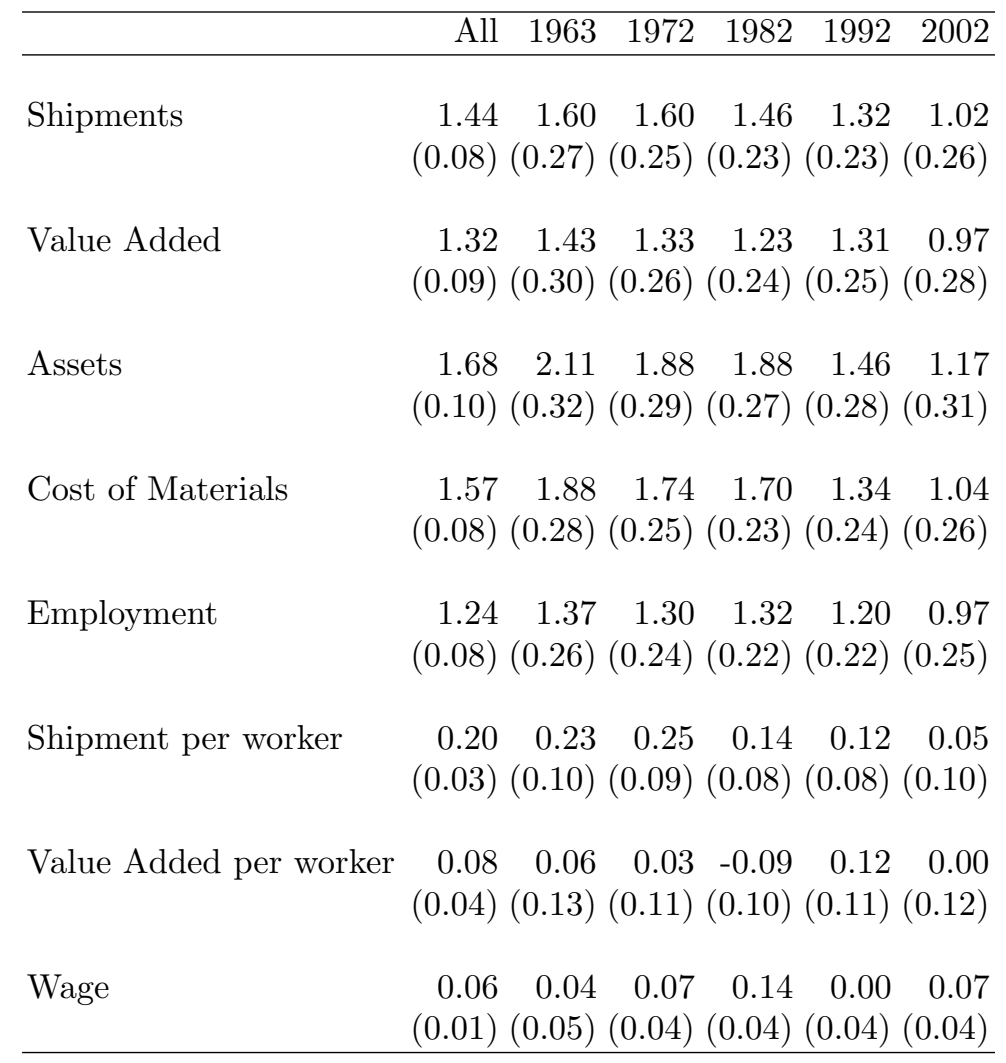

Note: Estimates display the log of the ratio of the mean for VI plants over the mean for MM plants. Thus 1.44 in the top left cell indicates that the average vertically integrated plant ships 144 percent more than the average minimill, or equivalently 4.2 times more. Year Controls included in each regression. There are a total of 1499 observations in these regressions. 
Table 4: Production by Product

\begin{tabular}{lrrrrrrrrr}
\hline Year & HRS & HRB & CRS & Ingots & P\&T & Blast & CFB & Wire & Other \\
\hline 1963 & 23 & 23 & 16 & 13 & 7 & 5 & 1 & 2 & 9 \\
1967 & 21 & 23 & 14 & 13 & 7 & 5 & 1 & 2 & 14 \\
1972 & 27 & 23 & 16 & 10 & 6 & 5 & 1 & 2 & 9 \\
1977 & 26 & 22 & 17 & 10 & 8 & 7 & 1 & 1 & 8 \\
1982 & 30 & 21 & 15 & 8 & 11 & 5 & 1 & 1 & 9 \\
1987 & 38 & 20 & 17 & 8 & 5 & 3 & 1 & 1 & 7 \\
1992 & 37 & 21 & 16 & 8 & 5 & 4 & 2 & 1 & 7 \\
1997 & 35 & 21 & 17 & 7 & 6 & 4 & 2 & 1 & 7 \\
2002 & 31 & 22 & 23 & 7 & 6 & 2 & 2 & 2 & 6
\end{tabular}

Note: Fraction of Industry Output Accounted for by each product: Hot-rolled steel sheet (HRS), Hot-rolled bar (HRB), Cold-rolled sheet (CRS), Ingots and shapes, Pipe and tube (P \& T), Wire, Cold-finished bars (CFB), and coke oven and blast furnace products (Blast), Steel Wire (Wire). 
Table 5: Entry and Exit in U.S. steel

1963-1972 Entrant Market Share (Plants) Exitor Marke

$1973-1982$

1983-1992

1993-2002

$\underline{\text { Minimills }}$

1963-1972

1973-1982

1983-1992

1993-2002

Vertically Integrated

1963-1972

1973-1982

1983-1992

1993-2002

$6.2(29)$

$5.3(49)$

$20.7(55)$

$12.2(30)$

Entrants

17

39

43

D*

Entrants

12

10

12

D*
Exitor Market Share (Plants)

$9.4(\mathrm{D} *)$

$19.5(20)$

$18.0(47)$

$1.7(41)$

$\underline{\text { Exitors }}$

$\mathrm{D} *$

0

26

17

Exitors

D*

20

21

24

Note: $\mathrm{D} *$ cannot be disclosed due to the small number of observations. 
Table 6: Production Function

\begin{tabular}{|c|c|c|c|c|c|c|}
\hline \multirow[t]{2}{*}{ Dep Variable } & \multicolumn{3}{|c|}{$\begin{array}{l}\text { Panel A: Output Deflated } \\
\text { by Steel Price Index }\end{array}$} & \multicolumn{3}{|c|}{$\begin{array}{c}\text { Panel B: Output Deflated } \\
\text { by Product Prices }\end{array}$} \\
\hline & $\mathrm{I}$ & II & III(GMM) & IV & $\mathrm{V}$ & VI (GMM) \\
\hline Labor & $\begin{array}{c}0.297 \\
(0.010)\end{array}$ & $\begin{array}{c}0.326 \\
(0.013)\end{array}$ & $\begin{array}{c}0.266 \\
(0.024)\end{array}$ & $\begin{array}{c}0.290 \\
(0.010)\end{array}$ & $\begin{array}{c}0.324 \\
(0.010)\end{array}$ & $\begin{array}{c}0.261 \\
(0.036)\end{array}$ \\
\hline Materials & $\begin{array}{c}0.648 \\
(0.010)\end{array}$ & $\begin{array}{c}0.616 \\
(0.011)\end{array}$ & $\begin{array}{c}0.658 \\
(0.031)\end{array}$ & $\begin{array}{c}0.667 \\
(0.011)\end{array}$ & $\begin{array}{c}0.634 \\
(0.011)\end{array}$ & $\begin{array}{c}0.683 \\
(0.038)\end{array}$ \\
\hline Capital & $\begin{array}{c}0.047 \\
(0.006)\end{array}$ & $\begin{array}{c}0.055 \\
(0.009)\end{array}$ & $\begin{array}{c}0.093 \\
(0.020)\end{array}$ & $\begin{array}{c}0.050 \\
(0.007)\end{array}$ & $\begin{array}{c}0.055 \\
(0.009)\end{array}$ & $\begin{array}{c}0.091 \\
(0.020)\end{array}$ \\
\hline VI (alone) & $\begin{array}{c}-0.049 \\
(0.017)\end{array}$ & & $\begin{array}{l}-0.080 \\
(0.037)\end{array}$ & $\begin{array}{c}-0.085 \\
(0.018)\end{array}$ & & $\begin{array}{l}-0.111 \\
(0.039)\end{array}$ \\
\hline VI & & $\begin{array}{l}-0.098 \\
(0.031)\end{array}$ & $\begin{array}{l}-0.198 \\
(0.074)\end{array}$ & & $\begin{array}{l}-0.124 \\
(0.031)\end{array}$ & $\begin{array}{l}-0.246 \\
(0.077)\end{array}$ \\
\hline $\begin{array}{l}\text { VI } \\
\times \text { Year }\end{array}$ & & $\begin{array}{c}0.003 \\
(0.001)\end{array}$ & $\begin{array}{c}0.006 \\
(0.003)\end{array}$ & & $\begin{array}{c}0.003 \\
(0.001)\end{array}$ & $\begin{array}{c}0.006 \\
(0.003)\end{array}$ \\
\hline $\begin{array}{l}\text { Year FE } \\
\text { Constant }\end{array}$ & $\begin{array}{l}-0.370 \\
(0.051) \\
\end{array}$ & $\begin{array}{c}\mathrm{X} \\
-0.577 \\
(0.071) \\
\end{array}$ & $\begin{array}{l}-0.776 \\
(0.025) \\
\end{array}$ & $\begin{array}{c}-0.453 \\
(0.052) \\
\end{array}$ & $\begin{array}{c}\mathrm{X} \\
-0.620 \\
(0.072) \\
\end{array}$ & $\begin{array}{l}-0.802 \\
(0.025) \\
\end{array}$ \\
\hline $\begin{array}{l}R^{2} \\
\text { Observations }\end{array}$ & 0.97 & 0.97 & & 0.97 & 0.97 & \\
\hline Observations & 1499 & 1499 & 1499 & 1499 & 1499 & 1499 \\
\hline
\end{tabular}

Note: GMM indicates a two-stage investment control function procedure with a selection adjustment was used. More detail on this procedure is provided in Appendix C.2. In Column III and VI, the VI (alone) term is estimated by projecting estimating productivity on an indicator for a vertically integrated plant, while the VI and VI $\times$ year term indicates the same projection with an additional year interaction term. Standard errors are clustered at the plant-level to control for heteroskedasticity and serial correlation. For columns III and VI this clustering is computed via block bootstrap which in addition corrects for the multi-step nature of the GMM estimator. 
Table 7: Decomposing Productivity Growth: Within and Between Technology (1963-2002)

Panel A: All Plants and Between Technology

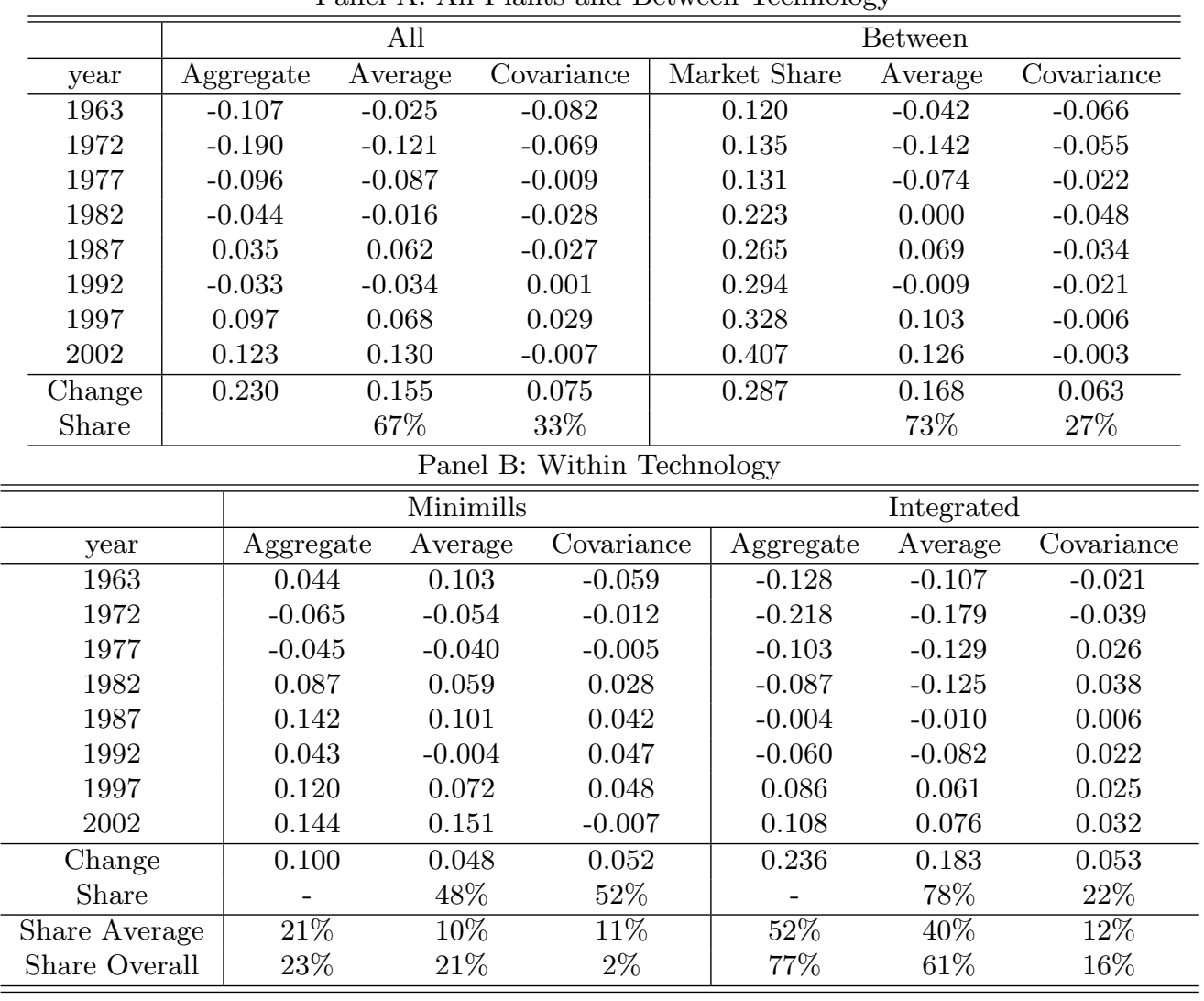

Note: All the entries are in logs. Summing the market share weighted technology specific aggregate productivity measures results in the numbers listed under the Aggregate column of All plants in Panel A. For example for the year 2002 the aggregate productivity term is 0.123 and this is given by $(0.144 * 0.407)+(0.108 * 0.593)$. The market share by technology is listed in Panel A. The Share Average entries in Panel B reflect the share of the relevant component in the between average component listed in Panel A. For instance the Share Average of minimills, 10\%, is obtained using $0.5 * 0.048 / 0.23$. The four components, average and covariance by technology, sum up to the share of the between average share in Panel A, i.e. 73\%. The Share Overall entries in Panel B are obtained by multiplying the specific component (average and covariance) by the relevant market share. For example the share of the minimills within productivity growth term in the overall aggregate productivity growth (of $21 \%$ ) is obtained as follows: $(0.151 * 0.407-0.103 * 0.12) / 0.23$. As mentioned in the text if the market shares are equal (at 0.5 ) the between covariance is zero by construction, and it would also imply that the technology specific aggregate productivity would simply be $1 / 2$ of the industry's aggregate productivity. We omit census year 1967 due lack of reliable capital stock data for that year. 
Table 8: Dynamic Decomposition of Productivity Growth (Eq. (5))

\begin{tabular}{cccc}
\hline \hline Component & All & Minimill & Integrated \\
\hline Total Change & 0.231 & 0.101 & 0.235 \\
Within (\%) & 34 & 107 & 33 \\
Reallocation (\%) & 47 & -7 & 48 \\
Net Entry (\%) & 19 & 0 & 19 \\
Total Reallocation (\%) & 66 & -7 & 67 \\
\hline
\end{tabular}

Entry-Exit Premium By Period and Technology

\begin{tabular}{ccc}
\multicolumn{3}{c}{$\left(\sum_{i \in B} s_{i t} \omega_{i t}-\sum_{i \in C} s_{i t-1} \omega_{i t-1}\right)$} \\
\hline Period & Minimill & Integrated \\
\hline $1963-1972$ & -0.008 & -0.012 \\
$1972-1982$ & -0.040 & 0.018 \\
$1982-1992$ & -0.009 & -0.002 \\
$1992-2002$ & 0.040 & 0.040 \\
\hline Total & 0.00 & 0.044 \\
\hline \hline
\end{tabular}


Figure 1: Evolution of the Steel Industry, and Vertically Integrated Mills and Minimills
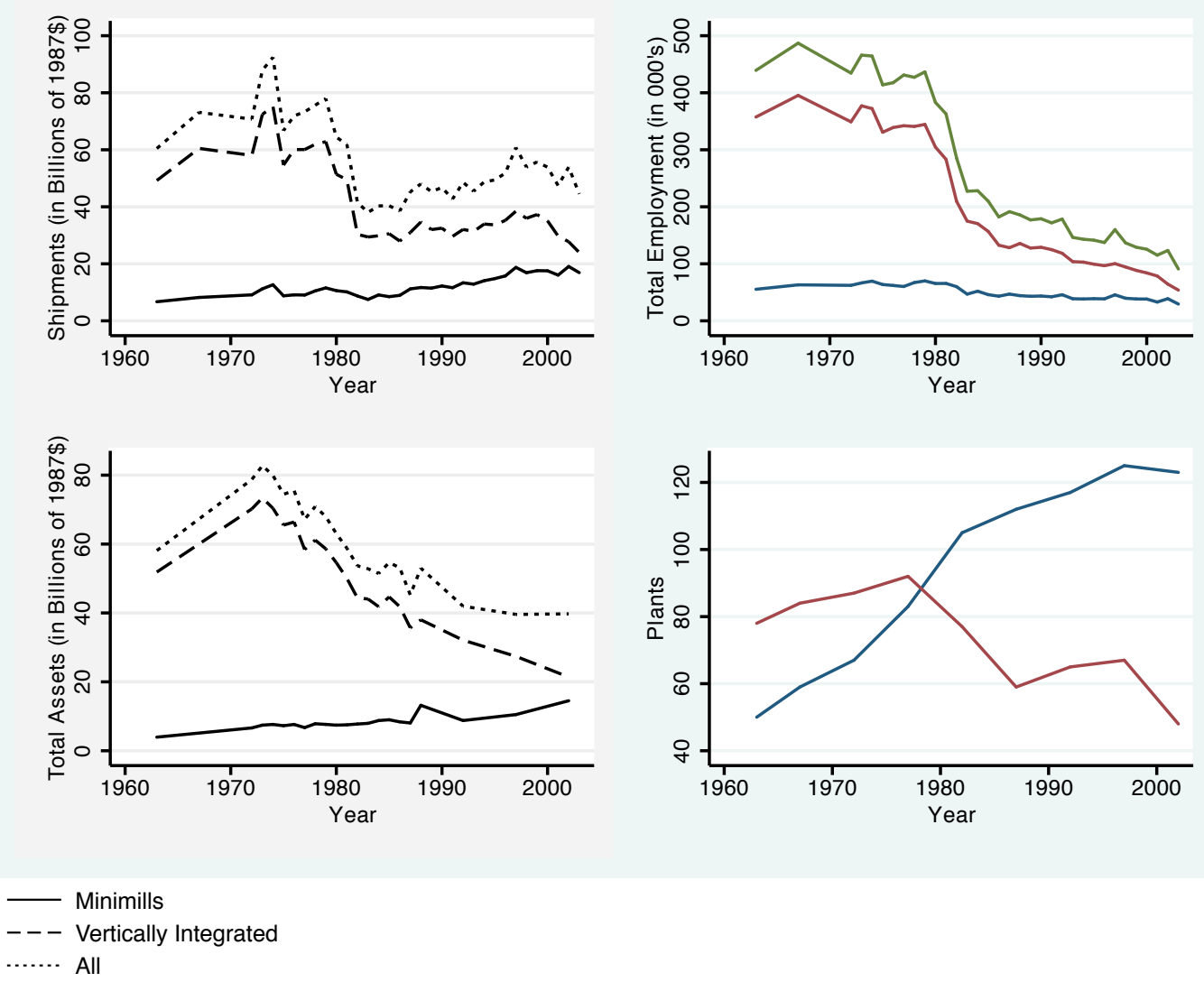
Figure 2: Minimills Market share by Major Product.

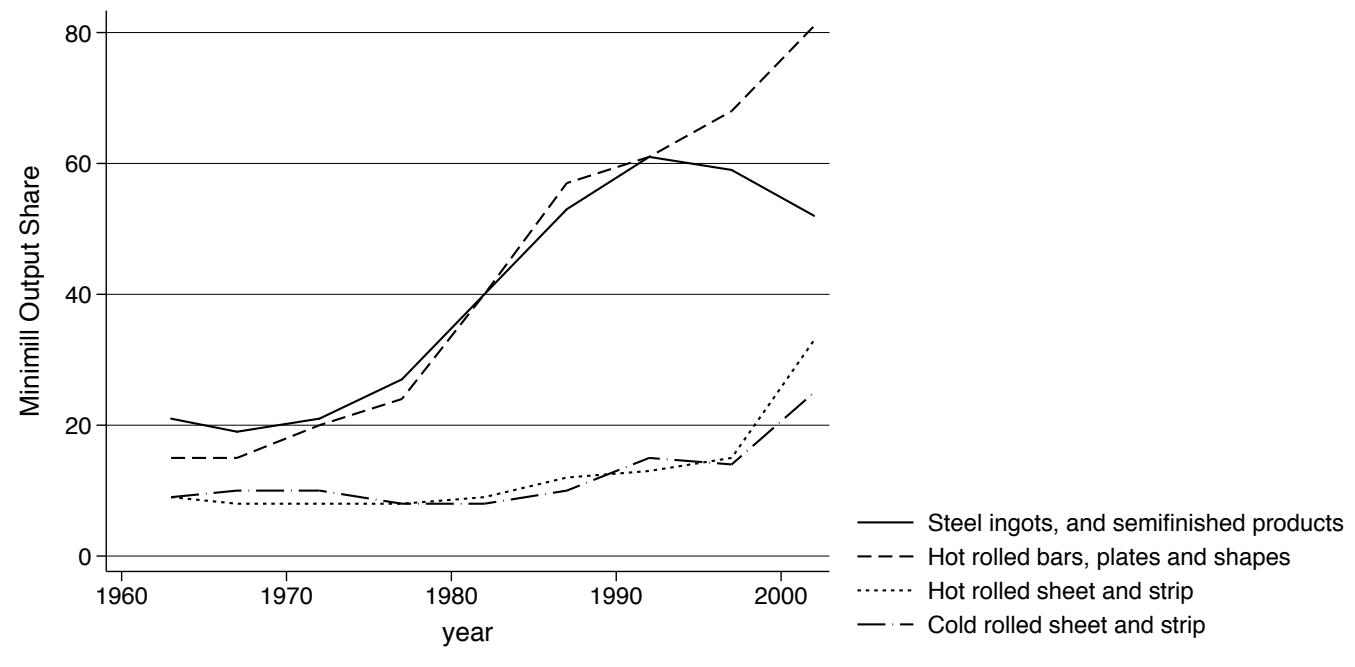


Figure 3: Producer Price Index by Product Segment

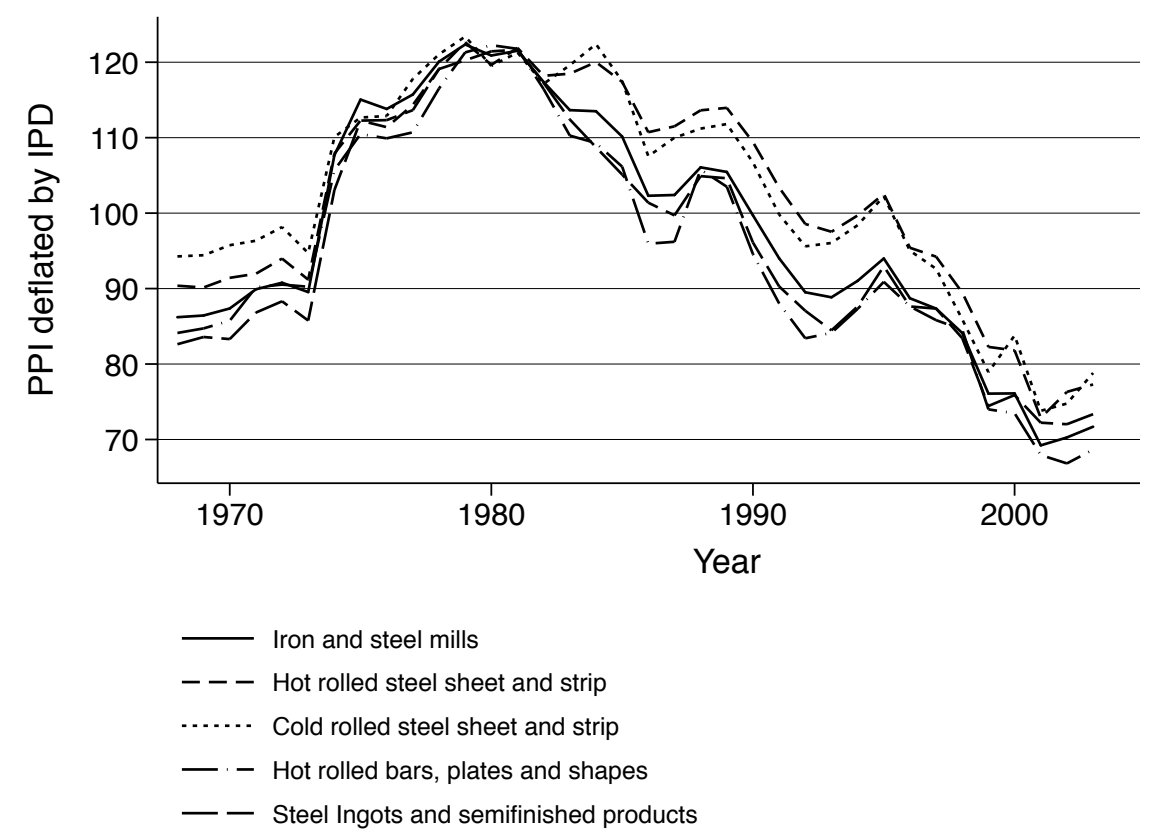

Note: Producer Price Index for Selected Steel Products deflated by GDP Deflator. Base year $1987=100$. Source: BLS. 
Figure 4: Market Share Weighted Markups

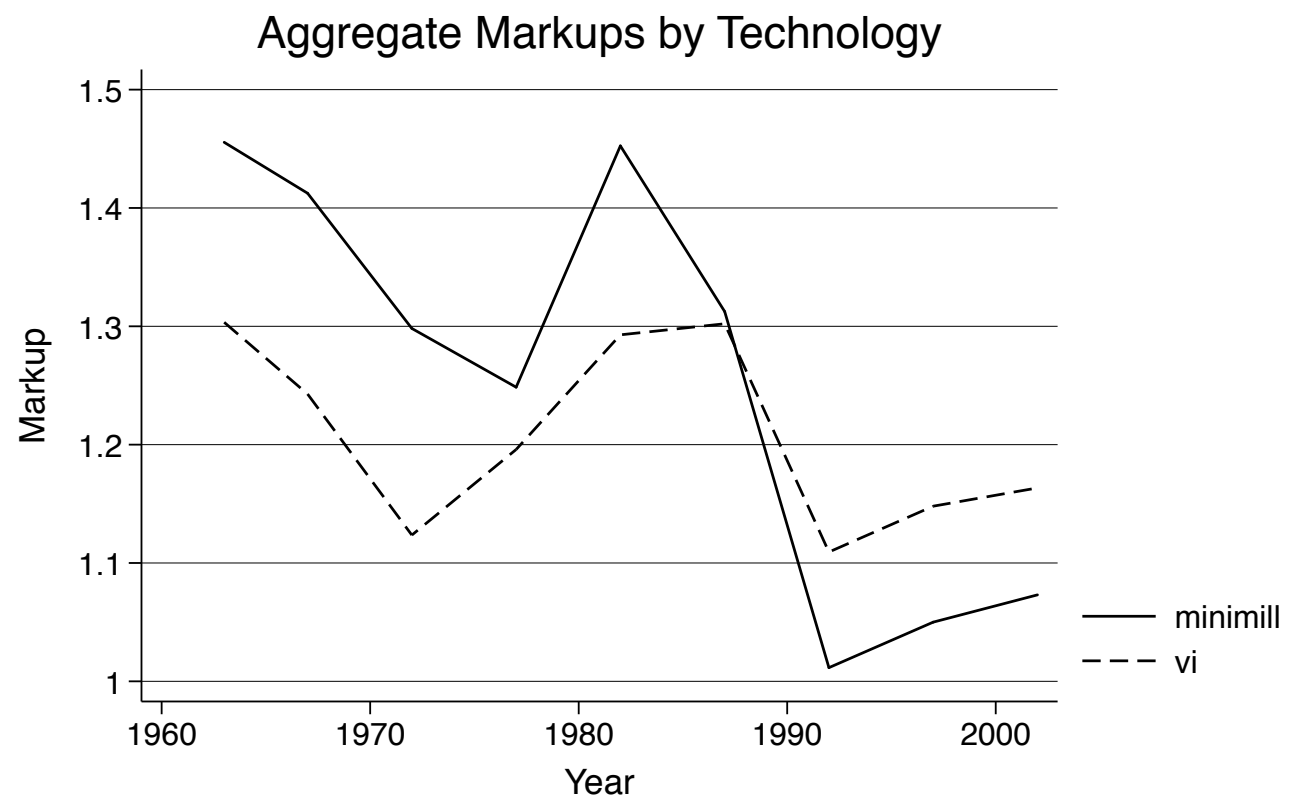

Source: Own calculations using US Census data. 


\section{A Data Appendix}

\section{A.1 Sample Selection}

We pull all plants in the Census of Manufacturing, Annual Survey of Manufacturing and Longitudinal Business Database from 1963 to 2007 coded in either NAICS 33111 or SIC 3312 at some point in their lives.

The Longitudinal Business Database has worse industry coding than the Census of Manufacturing, and taking its coding literally introduces a large number of non-steel mills into the sample. ${ }^{45}$ Therefore, we only include a plant in the sample if it has been coded in steel in either the CMF or the ASM.

\section{A.2 Coding Minimills, Vertically Integrated, and Rolling Plants}

A primary issue in understanding the Steel industry is how to code plants as being either minimills, vertically integrated or rolling and processing plants.

The 2007, 2002 and 1997 Census of Manufacturing have a special inquiry questionnaire for the steel industry (henceforth SI) appended to it. This questionnaire asks plants if they are considered to be a minimill or not. Moreover, the SI also asks for plant hours in electric arc furnaces, blast furnaces, coke ovens, and basic oxygen furnaces. If a plant reports plant hours in coke, blast, or basic oxygen furnace, we flag this plant as a vertically integrated plant, since vertically integrated plants are defined by the production process which first produces pig iron and slag, and then processes the result in a basic oxygen furnace. If a plant reports being a minimill or if it reports hours in an electric arc furnace, then we code this plant as a minimill. ${ }^{46}$

Some vertically integrated plants occasionally have electric arc furnaces. Whenever a plant report hours in an electric arc furnace and in a basic oxygen or blast furnace, we assign this plant to the vertically integrated category. The reason is that the vertically integrated section of the plant is usually far bigger than the electric furnace section.

Many plants do not report hours in any steel mill department, and do not report being minimills either. We call these plants rolling mills or processors, as they do not produce steel per se, but process steel products. For instance, a rolling mill might use steel ingots, blooms and billets (steel shapes), and roll these into steel sheet. Alternatively, a mill might take steel rods and shape them into steel screws.

For plants that are still in operation in 1997, or were built after 1997, the SI file is all we need to identify the plant's type. However, for plants that shut down pre-1997 we use the material and product trailer to the Census of Manufacturing to classify them.

Minimills can be identified by their input use. Electric arc furnaces use a combination of scrap steel and direct-reduced iron as inputs. Thus, if a plant uses any direct-reduced iron, we flag this plant as a minimill. Likewise, if scrap steel represents more than $20 \%$ of a plant's material use, we flag this plants as a minimill. ${ }^{47}$

Vertically integrated plants can also be identified from their input use. If a plant uses "Coal for Coke" this is a good indication that a plant has a blast furnace. We flag rolling

\footnotetext{
${ }^{45}$ In particular, the Zip Business Patterns database, which uses the same underlying source as the LBD, has a large number of entrants coded in NAICS 33111 from 1997 to 2002 which are not steel mills.

${ }^{46}$ For references on the differences between minimills and vertically integrated plants, see Fruehan (1998) p.1-12, Crandall (1981) p.5-15.

${ }^{47}$ Basic oxygen furnaces at vertically integrated plants also can a take a small percent of scrap steel. For this reason, we only flag a plant as a minimill if scrap steel is a large part of their inputs.
} 
mills by their use of "Steel Shapes and Forms" in other words, steel ingots and so on that are shaped into steel products.

We also use the product trailer to categorize plants. If a plant produces "Coke Oven or Blast Furnace Products" we flag this plant as a vertically integrated. As well, if a plant produces "Cold Rolled Sheet Steel" before 1980, we flag this plant as vertically integrated, as minimills only started producing cold rolled sheets in the mid 80's. For references on the changing ability of minimills to produce sheet products, see Rogers (2009) page 162 and chapter 8 of Hall (1997).

Plants are not always consistently coded either minimills, vertically integrated, or rolling mills from one year to another. Thus we classify a plant based on its history of such flags. Specifically, a plant is vertically integrated if it is flagged as such at least $80 \%$ of the time. Likewise, a plant is assigned to the minimill category if it is flagged as such at least $80 \%$ of time.

Since vertically integrated plants, as their name suggests, are typically engaged in multiple activities, such as having an electric arc furnace and a basic oxygen furnace, along with a rolling mill, we first flag plants as vertically integrated or not, then flag the remaining plants as minimills. Leftover plants are assigned to be rolling mills.

\section{A.3 Coding Products}

We use the product trailer of the Census Bureau to investigate the products produced by steel producers. We categorize products into the following types shown in Table 9. These are responsible for 93 percent of output not categorized as "other" or "unclassified" in 1997.

\begin{tabular}{ll} 
Product & Product Codes \\
\hline Hot-Rolled Steel Bar & SIC 33124, NAICS 3311117 \\
Hot Rolled Sheet and Strip & SIC 33123, NAICS 3311115 \\
Cold Rolled Sheet and Strip & SIC 33127, SIC 33167 \\
& NAICS 3312211, NAICS 3312211D \\
Cold Finished Bars and Bar Shapes & SIC 33128, SIC 33168 \\
& NAICS 3312213, NAICS 331111F \\
Steel Ingots and Semi-Finished Shapes & SIC 33122, NAICS 3311113 \\
Steel Wire & SIC 33125, SIC 33155 \\
& NAICS 3312225, NAICS 3311119 \\
Steel Pipe and Tube & SIC 33170, SIC 33177 \\
& NAICS 3312100, NAICS 331111B
\end{tabular}

Table 9: Description of Product Codes 


\section{B Additional Tables and Figures}

Table 10: Growth of Market Share for Minimills and Vertically Integrated Plants

\begin{tabular}{lrrrrr}
\hline \multicolumn{7}{l}{ Industry-wide Growth Rate of: } \\
\hline Year & Shipments & Employment & Capital & Materials & TFP \\
\hline $1963-1967$ & 20 & 10 & $\cdot$ & 25 & 5 \\
$1967-1972$ & -2 & -11 & - & 7 & -5 \\
$1972-1977$ & 3 & -2 & -16 & -2 & -1 \\
$1977-1982$ & -56 & -40 & -22 & -64 & -6 \\
$1982-1987$ & 8 & -42 & -17 & 9 & 11 \\
$1987-1992$ & -6 & -7 & 26 & 7 \\
$1992-1997$ & 7 & -12 & -8 & 20 & 16 \\
$1997-2002$ & 23 & -34 & -5 & -21 & 0 \\
\hline & -20 & Minimills: & & & \\
\hline $1963-1967$ & 0 & 1 & - & 0 & 2 \\
$1967-1972$ & 0 & 0 & 2 & 1 & 2 \\
$1972-1977$ & 2 & 7 & 5 & 1 & 4 \\
$1977-1982$ & 0 & 5 & 4 & 6 & 10 \\
$1982-1987$ & 9 & 1 & 3 & 5 & 8 \\
$1987-1992$ & 4 & 3 & 6 & 3 & 1 \\
$1992-1997$ & 3 & 6 & 13 & 8 & 7 \\
$1997-2002$ & 3 & & & & \\
\hline
\end{tabular}

\section{Measuring Productivity and Markups}

We briefly discuss how we estimate productivity and recover markups using our plant-level panel on production and prices. This discussion will follow the exposition of control function estimation of productivity in Ackerberg, Frazer, and Caves (2006).

\section{C.1 Deflators}

Our measure of output is sales, while we wish to use a production function based on quantities. We define quantity $Q_{i t}$ as $Q_{i t}=S_{i t} / P_{i t}$; deflated sales. We use two approaches to compute the price deflator $P_{i t}$. First, we use a common price deflator $P_{t}$ based on the Bureau of Labor Statistics steel price index PCU331111331111. Second, we use product specific price deflators $P_{j t}$ from the BLS (shown in Figure 3), where $j$ indexes products, and create a plant-specific price index $P_{i t}$ using a revenue weighted price index:

$$
P_{i t}=\sum_{j \in J} \frac{S_{i j t}}{S_{i t}} P_{j t}
$$

where $S_{i j t}$ are plant $i$ 's shipments of product $j$. For products without a specific price index (such as product "not elsewhere classfied") we use the price index $P_{t}$ for steel as a whole. 


\section{C.2 Productivity}

We take the (log of) the production function introduced in equation (2) to the data:

$$
y_{i t}=f_{\psi, t}\left(L_{i t}, M_{i t}, K_{i t} ; \boldsymbol{\beta}\right)+\omega_{i t}+\epsilon_{i t}
$$

Unanticipated shocks to production and measurement error in output are captured by $\epsilon_{i t}$, and we denote $y_{i t}=\ln \left(Q_{i t}\right)+\epsilon_{i t}$. The technology subscript $\psi$ highlights that we allow for the production function to vary across minimills and vertical integrated producers.

We follow the standard in the literature and rely on a plant's optimal investment equation to control for unobserved productivity shocks. Anticipating our markup analysis we specifically allow for intermediate inputs to be a variable input facing no adjustment costs, and include all relevant input demand variables such as wages, a firm's export status, in addition to their capital, labor and material use. ${ }^{48}$

Specifically, the first-stage of this procedure runs output $y_{i t}$ on a flexible function of inputs $\left(l_{i t}, m_{i t}, k_{i t}\right)$, an investment control function $i_{i t}$, as well as year-plant type controls. In other words:

$$
y_{i t}=\phi_{\psi, t}\left(l_{i t}, m_{i t}, k_{i t}, i_{i t}\right)+\epsilon_{i t}
$$

And productivity is recovered as $\omega_{i t}=\hat{\phi}_{i t}-f_{\psi, t}\left(L_{i t}, M_{i t}, K_{i t} ; \boldsymbol{\beta}\right)$. A key component into the estimation routine is the law of motion on productivity. In our baseline results we stick to an exogenous Markov process given by

$$
\omega_{i t}=g_{\psi}\left(\omega_{i t-1}, \hat{\chi}_{i t-1}\right)+\xi_{i t}
$$

Note that this evolution is allowed to vary for minimills and vertically integrated plants, as we have seen in the OLS regressions that vertically integrated plants slowly catch up to minimills. Moreover, we control for the selection effect due to the fact that we only observed productivity conditionally on a plant remaining in the industry using the estimated propensity score of exiting $\hat{\chi}_{i t}$. To the extent that vertically integrated plant are larger and thus at an ex-ante level more likely to remain in the industry, this will generate differential selection rules for minimills and vertically integrated plants.

We recover estimates of the production function coefficients, $\boldsymbol{\beta}$, by forming moments on this productivity shock $\xi_{i t}$. The identification of these coefficients relies on the rate at which inputs adjust to these shocks. In particular we allow both labor and capital to be dynamically chosen inputs, whereby current values of capital (labor) do not react to current shocks to productivity $\left(\xi_{i t}\right)$. Plants do, however, adjust their intermediate input use (scrap, energy, other material inputs) to the arrival of a productivity shock $\xi_{i t}$.

The exact moments will depend on the functional form we select for $f($.$) . For example$ for the well known Cobb-Douglas production function we estimate the production function coefficients using the following moments:

$$
E\left(\xi_{i t}(\boldsymbol{\beta})\left(\begin{array}{c}
l_{i t} \\
m_{i t-1} \\
k_{i t}
\end{array}\right)\right)=0
$$

As a recent literature (Ackerberg, Frazer, and Caves, 2006) has pointed out that the identification of the variable input, the coefficient on $m_{i t}$ in our case, relies on sufficient

\footnotetext{
${ }^{48}$ See De Loecker and Warzynski (forthcoming) for more details
} 
variation in plant-level input prices which are serially correlated over time. ${ }^{49}$

\section{C.3 Estimating Markups}

Our approach to recovering markups follows De Loecker and Warzynski (forthcoming). In the rest of this section we briefly review the approach. In addition to the production function we introduced before, we only have to assume that producers active in the market minimize costs. Let $\mathbf{V}_{i t}$ denote the vector of variable inputs used by the firm. We use the vector $\mathbf{K}_{i t}$ to denote dynamic inputs of production. Any input that faces adjustment costs will fall into this category; capital is an obvious one, but our framework allows us to also include labor.

The associated Lagrangian function is:

$$
L\left(V_{i t}^{1}, \ldots, V_{i t}^{V}, \mathbf{K}_{i t}, \lambda_{i t}\right)=\sum_{v=1}^{V} P_{i t}^{v} V_{i t}^{v}+\mathbf{r}_{i t} \mathbf{K}_{i t}+\lambda_{i t}\left(Q_{i t}-Q_{i t}\left(V_{i t}^{1}, \ldots, V_{i t}^{V}, \mathbf{K}_{i t}, \omega_{i t}\right)\right)
$$

where $P_{i t}^{v}$ and $\mathbf{r}_{i t}$ denote a firm's input prices for a variable input $v$ and dynamic inputs, respectively. The first order condition for any variable input free of adjustment costs is

$$
\frac{\partial L_{f t}}{\partial V_{i t}^{v}}=P_{i t}^{v}-\lambda_{i t} \frac{\partial Q_{i t}(.)}{\partial V_{i t}^{v}}=0
$$

where the marginal cost of production at a given level of output is $\lambda_{i t}$, as $\frac{\partial L_{i t}}{\partial Q_{i t}}=\lambda_{i t}$. Rearranging terms and multiplying both sides by $\frac{V_{i t}}{Q_{i t}}$, generates the following expression.

$$
\frac{\partial Q_{i t}(.)}{\partial V_{i t}^{v}} \frac{V_{i t}^{v}}{Q_{i t}}=\frac{1}{\lambda_{i t}} \frac{P_{i t}^{v} V_{i t}^{v}}{Q_{i t}}
$$

Cost minimization implies that optimal input demand is realized when a firm equalizes the output elasticity of any variable input $V_{i t}^{v}$ to $\frac{1}{\lambda_{i t}} \frac{P_{i t}^{v} V_{i t}}{Q_{i t}}$.

Define markup $\mu_{i t}$ as $\mu_{i t} \equiv \frac{P_{i t}}{\lambda_{i t}}$. As De Loecker and Warzynski (forthcoming) show, the cost-minimization condition can be rearranged to write markup as:

$$
\mu_{i t}=\theta_{i t}^{v}\left(\alpha_{i t}^{v}\right)^{-1}
$$

where $\theta_{i t}^{v}$ denotes the output elasticity on an input $V^{v}$ and $\alpha_{i t}^{v}$ is the revenue share of variable input $v$, defined by $\frac{P_{i t}^{v} V_{i t}^{v}}{P_{i t} Q_{i t}}$, which is data. This expression will form the basis for our approach: we obtain the output elasticity from the estimation of a production function and only need to measure the share of an input's expenditure in total sales.

\section{Linking Markups to Reallocation: An Example}

This section outlines the relationship between markups and the covariance between a firm's productivity and market share. The link between markups and covariances is due to changes in the elasticity of the residual demand curve.

\footnotetext{
${ }^{49}$ All our results will be invariant to modifications of the timing assumptions discussed in the main text. Our approach is flexible and can allow for a variety of production functions combined with various assumptions on the variability of inputs.
} 
Suppose that the production technology is constant returns to scale with a single input of capital $K$ :

$$
Q^{S}=B K
$$

And there is a residual demand curve faced by the firm with elasticity $\epsilon$ given by:

$$
Q^{D}=A P^{-\epsilon}
$$

The firm's sales are given by:

$$
S=P \times Q=K^{1-\frac{1}{\epsilon}} A^{-\frac{1}{\epsilon}} B^{1-\frac{1}{\epsilon}}
$$

And the firm's profit function is thus:

$$
\begin{aligned}
\pi & =S-r K \\
& =K^{1-\frac{1}{\epsilon}} \underbrace{A^{-\frac{1}{\epsilon}} B^{1-\frac{1}{\epsilon}}}_{\omega}-r K
\end{aligned}
$$

and thus solving for the firm's first order condition gives:

$$
K=\left(\frac{\beta \omega}{r}\right)^{\frac{1}{1-\beta}}
$$

where $\beta=\left(1-\frac{1}{\epsilon}\right)$. This gives sales $S$ by:

$$
S=\omega^{-\epsilon}\left(\frac{\beta}{r}\right)^{\frac{\beta}{1-\beta}}
$$

In other words, the elasticity of output with respect to productivity is $\epsilon$. Notice that the presence of fixed assets, time to build, or any adjustment costs will introduce a dynamic aspect to the firm's optimal response to changes in productivity, and typically lowers the elasticity of output with respect to productivity. See Asker, Collard-Wexler, and De Loecker (2012) for a discussion of this type of model.

Note that the markup is given by the usual formula:

$$
\mu=\frac{1}{1+\frac{1}{\epsilon}}
$$

Define the weighted sum $\Omega$ as:

$$
\Omega=\left(\sum_{i}^{N} s_{i}\right)^{-1} \sum_{i}^{N} s_{i} \omega_{i}
$$

and the unweighted sum as

$$
\bar{\omega}=\sum_{i}^{N} \omega_{i}
$$


This implies that:

$$
\Omega=\frac{\sum_{i}^{N} \omega_{i}^{1-\epsilon}}{\sum_{i}^{N} \omega_{i}^{-\epsilon}}
$$

Suppose that $\omega \sim \log \mathcal{N}(\mu, \sigma)$. Remember that the mean of the log-normal is $E[\omega]=$ $\exp \left(\mu+\frac{1}{2} \sigma^{2}\right)$, and $\omega^{\alpha} \sim \log \mathcal{N}\left(\alpha \mu, \alpha^{2} \sigma\right)$ Then:

$$
E\left[\omega^{\sigma}\right]=\exp \left(\alpha \mu+\frac{1}{2} \alpha^{2} \sigma^{2}\right)
$$

Putting this into the previous equation:

$$
\begin{aligned}
\Omega & =\frac{\exp \left((1-\epsilon) \mu+\frac{1}{2}(1-\epsilon)^{2} \sigma^{2}\right)}{\exp \left(-\epsilon \mu+\frac{1}{2} \epsilon^{2} \sigma^{2}\right)} \\
& =\exp \left(\mu+\frac{1}{2} \sigma^{2}-\epsilon \sigma^{2}\right)
\end{aligned}
$$

And thus the covariance is:

$$
\operatorname{Cov}=\Omega-\bar{\omega}=\exp \left(\mu+\frac{1}{2} \sigma^{2}-\epsilon \sigma^{2}\right)-\exp \left(\mu+\frac{1}{2} \sigma^{2}\right)
$$

which becomes larger as $\epsilon$ becomes more negative. 